Evaluasi: Jurnal manajemen Pendidikan Islam

ISSN (P): 2580-3387, ISSN (E): 2615-2886

DOI : http://doi.org/10.32478/evaluasi.v5i2.673

Article Type : Original Research Article

\title{
ASPEK SUSTAINABILITAS DI PERGURUAN TINGGI ISLAM: ANTARA KONSEP DAN PRAKTIK KEPEMIMPINAN BERKELANJUTAN
}

\author{
Muhammad Haekal \\ Universitas Islam Negeri Ar-Raniry, Aceh, Indonesia \\ Corresponding author: muhammad.haekal@ar-raniry.ac.id \\ Submission Track: \\ Submisson : : 15-05-2021 \\ Accept Submission : 19-07-2021 \\ Avaliable Online : 11-09-2021
}

Copyright @ 2021 Author

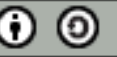

This work is licensed under a Creative Commons Attribution-ShareAlike 4.0

\begin{abstract}
This qualitative research examines the implementation of sustainability issues in Islamic universities in Aceh, Indonesia. This research methodology used document review and observation as the main elements. For data analysis, the researchers combined LaTrobe University's sustainability metrics and Edgar Schein's Three Levels of Culture concept. The results showed that the sample university did not have a real concept regarding the issue of sustainability, but had a vague implementation of the 'hidden sustainability' aspect. This study recommends that university begin to think seriously about the aspects of sustainability in order to provide tangible benefits, especially in environmental and socio-economic aspects.
\end{abstract}

Keywords. Educational management; Higher education; Sustainability.

Abstrak
Penelitian kualitatif ini mengkaji implementasi isu sustainabilitas di perguruan
tinggi Islam di Aceh, Indonesia. Metodologi penelitian ini menggunakan kajian
dokumen serta observasi sebagai unsur utama. Untuk analisis data, peneliti
mengombinasikan metrik sustainabilitas LaTrobe University dan konsep Three
Levels of Culture Edgar Schein. Hasil penelitian menunjukkan perguruan tinggi
sampel belum memiliki konsep yang nyata terkait isu sustainabilitas, namun
memiliki implementasi yang samar-samar pada aspek 'sustainabilitas
tersembunyi'. Penelitian ini merekomendasikan agar perguruan tinggi mulai


memikirkan aspek sustainabilitas secara serius guna memberikan manfaat yang nyata, khususnya di aspek lingkungan serta sosial-ekonomi.

Keywords. Manajemen pendidikan; Perguruan tinggi; Sustainabilitas.

\section{A. PENDAHULUAN.}

Kepemimpinan berkelanjutan adalah konsep pada level individu atau organisasi yang berkaitan dengan komitmen hidup bijak terutama pada aspek lingkungan, masyarakat, dan ekonomi (Ferdig, 2007). Definisi dan arti kepemimpinan keberlanjutan bersifat homogen dengan kepemimpinan yang bertanggung jawab (Székely \& Knirsch, 2005). Aspek sustainabilitas ini perlu dipikirkan karena dalam praktiknya, sebagian entitas, termasuk institusi pendidikan, cenderung mengejar keuntungan maksimal tanpa memikirkan keselamatan pekerja dan lingkungan.

Salah satu manifestasi kepemimpinan berkelanjutan dapat dilihat melalui implementasi corporate social responsibility (CSR) di perusahaan. CSR adalah upaya organisasi melampaui pencapaian keuangan/ keuntungan dengan memahami dan menghormati masyarakat dan lingkungan selama prosesnya (Gebbels, Evans, \& Delany, 2011). Ada beberapa metode untuk mengetahui apakah sebuah perusahaan menerapkan aspek sustainabilitas atau tidak. Salah satu metode yang populer adalah dengan menggunakan standar GRI yang dikeluarkan oleh Global Sustainability Standards Board (GSSB). CSR sendiri selain merupakan praktik standar di antara perusahaan dan organisasi, juga praktik yang lazim pula di sebagian perguruan tinggi.

Perguruan tinggi adalah institusi yang dinamis dan terbuka di mana pengetahuan dihasilkan, termasuk wacana sustainabilitas (Beringer \& Adomßent, 2008). Salah satu contohnya adalah munculnya CSR di perguruan tinggi yang tertanam secara eksplisit dalam kurikulum dan aktivitasnya (Hopkinson, Hughes, \& Layer, 2008). Penyebaran isu sustainabilitas dalam pendidikan diharapkan dapat membantu anggota masyarakat, khususnya pemilik bisnis dan pembuat kebijakan, untuk memahami manfaatnya dalam mewujudkan masa depan yang lebih baik (Wang \& Juslin, 2012).

Dalam konteks nasional, Rosser dan Edwin (2010) menyatakan bahwa Indonesia pada tahun 2007 merupakan negara pertama yang memperkenalkan kewajiban CSR bagi setiap perusahaan, meskipun kesepakatan nakal di antara pemilik bisnis dan politisi masih dapat ditemukan. Di sisi lain, praktik sustainabilitas telah dikenal dan dilaksanakan sejak waktu yang sangat lama lalu oleh beberapa suku-suku asli di Indonesia (Basiago, 1995). Contoh paling mutakhir adalah Kasepuhan Ciptagelar yang berlokasi di Sukabumi, Jawa Barat (Watchdoc Image, 2015). Oleh karena itu, dalam penelitian ini, peneliti juga mencoba merefleksikan dan menganalisa apakah ada aspek 'sustainabilitas tersembunyi' (hidden sustainability) yang muncul di tengah masyarakat.

Secara umum, ditegaskan oleh Attas dan Ashraf (1979), tujuan pendidikan Islam adalah untuk mendisiplinkan fisik, intelektual, potensi spiritual dan kemampuan manusia, untuk mencapai harmoni dalam masyarakat. Senada dengan argumen 
tersebut, Beck (1974) berpendapat bahwa tujuan pendidikan adalah untuk mengembangkan daerah emosi, kognitif, dan perilaku, untuk mencapai kebahagiaan, kebebasan, kebijaksanaan, kesehatan bagi tiap individu. Selain itu, pendidikan diharapkan dapat membebaskan masyarakat dari eksploitasi dan penindasan (Darder, Baltodano, \& Torres, 2017). Pendidikan adalah jembatan untuk membantu umat manusia mendapatkan kehidupan yang lebih baik dan berkelanjutan. Dengan demikian, penting untuk menelusuri bagaimana perguruan tinggi di lingkup Kementerian Agama menangani isu-isu sustainabilitas. Pertanyaan penelitian dalam studi ini adalah: Apakah perguruan tinggi Islam di Aceh, Indonesia, baik secara implisit atau eksplisit, menangani dengan cermat isu lingkungan, sosial, dan ekonomi berkelanjutan?

\section{B. METODE PENELITIAN}

Penelitian kualitatif ini menggunakan analisis dokumen sebagai metode utama penelitian. Analisis dokumen adalah prosedur sistematis untuk meninjau atau mengevaluasi dokumen--baik materi cetak maupun elektronik (berbasis komputer dan ditransmisikan melalui Internet) (Bowen, 2009). Dokumen yang peneliti gunakan adalah milik salah satu perguruan tinggi Islam di Aceh. Peneliti menyamarkan identitas perguruan tinggi dengan maksud melindungi privasi kampus. Selain itu, penelitian ini juga memanfaatkan penelitian terdahulu sebagai komparasi, serta observasi nonpartisipan sebagaimana yang disarankan oleh kajian konseptual Savenye dan Robinson (2005). Untuk kepentingan analisis data, studi ini menggunakan metrik sustainabilitas dari La Trobe University sebagai pembanding, serta mengaitkan temuan dengan konsep three levels of culture (Schein, 2010).

Tabel B.1. Dampak lingkungan, sosial, ekonomi, dan rantai pasokan

\begin{tabular}{|c|c|c|}
\hline & $\begin{array}{c}\text { Rencana Berkelanjutan La Trobe } \\
\text { University 2015-2017 }\end{array}$ & \\
\hline Dampak Lingkungan & Dampak Sosial & $\begin{array}{l}\text { Dampak Ekonomi } \\
\text { dan Rantai Pasokan }\end{array}$ \\
\hline $\begin{array}{l}\text { - Emisi gas rumah } \\
\text { kaca, produksi dan } \\
\text { konsumsi energi } \\
\text { - Lingkungan } \\
\text { buatan } \\
\text { - Air } \\
\text { - Transportasi } \\
\text { - Kertas dan } \\
\text { - Lercetakan } \\
\text { - Limbah dan daur } \\
\text { ulang }\end{array}$ & $\begin{array}{l}\text { - Manfaat, pengembangan, dan kinerja } \\
\text { staf } \\
\text { - Rekrutmen dan promosi staf } \\
\text { - Keterlibatan dan kepuasan staf } \\
\text { - Kesehatan dan keselamatan Kerja } \\
\text { - Kesetaraan dan keragaman staf } \\
\text { - Dampak sosial ke para mahasiswa }\end{array}$ & $\begin{array}{l}\text { - Pembelian } \\
\text { - Perdagangan yang } \\
\text { adil } \\
\text { - Dampak ekonomi } \\
\text { langsung dan tidak } \\
\text { langsung }\end{array}$ \\
\hline
\end{tabular}


- Keanekaragaman hayati

Sumber: https://www.latrobe.edu.au/

Tabel B.2. Aspek teknis kebijakan berkelanjutan dan penelitian

\begin{tabular}{l|ll}
\hline Tata Kelola dan Manajemen Berkelanjutan & & \multicolumn{1}{c}{ Penelitian } \\
\hline - Pelaporan dan Pemantauan & $\bullet$ & Pendidikan untuk Generasi Mendatang \\
- Keterlibatan pemangku kepentingan dan & - Riset untuk Generasi Mendatang \\
$\quad$ komunikasi manajemen risiko & & \\
$\quad$ keberlanjutan & & \\
Sumber: https://www.latrobe.edu.au/ &
\end{tabular}

Sumber: https://www.latrobe.edu.au/

\section{HASIL DAN PEMBAHASAN}

Dalam mengevaluasi sebuah perguruan tinggi yang menjadi sampel, peneliti menemukan tantangan, antara lain terkait keterbatasan data publik dan akademis mengenai praktek sustainabilitas atau corporate social responsibility (CSR) yang kampus praktikkan. Kampus tidak merilis secara resmi mengenai hal tersebut, baik dalam laporan tahunan maupun rilis resmi lainnya. Namun, penelitian yang dilakukan oleh Nejati, Shafaei, Salamzadeh, dan Daraei (2011) menunjukkan bahwa dimungkinkan untuk menganalisis praktik CSR perguruan tinggi melalui situs resmi (website) kampus. Oleh karena itu, dalam studi ini, peneliti berfokus menyelidiki isu ini melalui situs resmi kampus sampel.

Di situs kampus, peneliti dapat menemukan manifestasi CSR secara terbatas. Tidak ada laporan resmi tentang sustainabilitas, baik dalam bentuk CSR atau lainnya. Namun ada sebuah berita tentang CSR yaitu pemberian beasiswa bagi mahasiswa yang tidak mampu. Program tersebut merupakan hasil kerjasama antara kampus dengan sebuah bank nasional. Meski demikian, peneliti berasumsi bahwa program CSR kemungkinan diinisiasi oleh bank, karena secara nasional hal tersebut sudah lazim dilakukan oleh korporasi Indonesia (Fitria \& Hartanti, 2010), termasuk lembaga keuangan seperti bank.

Mayoritas temuan peneliti adalah praktik 'sustainabilitas tersembunyi' seperti yang peneliti sampaikan di bagian pendahuluan. Hal ini kemungkinan terjadi karena tidak ada komentar eksplisit mengenai sustainabilitas sebagai 'tanggung jawab sosial institusi.' Selain dari itu, ada kegiatan lain seperti pengembangan sumber daya staf, maupun pelatihan mahasiswa. Misalnya pelatihan pedagogi, pelatihan hukum, seminar pemilu, sosialisasi pajak, pelatihan kewirausahaan, magang, dan pengabdian masyarakat di daerah terpencil. Selain itu, terdapat pula kegiatan yang berkaitan dengan kelestarian lingkungan, seperti seminar pelestarian sumber daya alam. Secara umum, dari penilaian terhadap situs resminya, kampus sampel hanya menunjukkan 
pemahaman dan perhatian yang terbatas terhadap aspek sustainabilitas. Pertanyaannya selanjutnya adalah: apakah itu kenyataan yang sebenarnya?

Schein (2010) dalam konsepnya three levels of cultures, berpendapat pemahaman terhadap sebuah organisasi atau institusi membutuhkan sebuah kajian mendalam terkait budaya yang termanifestasi dalam artefak, nilai yang dianut, serta asumsi dasar.

Mengenai artefak yaitu hal-hal yang terlihat secara jelas di organisasi (contoh arsitektur gedung, gaya berpakaian, kebersihan, dan lain sebagainya), menurut observasi peneliti, manifestasi positif sustainabilitas sulit ditemukan. Sebagai contoh, peneliti menemukan lampu-lampu di beberapa bagian gedung tetap menyala di pagi hingga siang hari. Sebagian staf dan siswa memperhatikan hal itu, tetapi mereka cenderung mengabaikan dan tidak berpikir mengenai penghematan konsumsi energi. Di samping itu, peneliti juga kesulitan menemukan adanya tempat sampah di kampus. Tidak heran, sampah kerap peneliti temukan berserakan di gedung kampus. Terkait aspek finansial institusi, belum ada rilis mengenai pendapatan dan belanja perguruan tinggi, sehingga sulit mengetahui dampaknya. Namun demikian, dalam observasi nonpartisipan peneliti, keluhan para staf atau tenaga pengajar yang tidak mendapatkan bayaran honor tepat waktu kerap terdengar. Kesulitan akses terhadap data-data penting perguruan tinggi ini mencerminkan rendahnya akuntabilitas yang sebenarnya merupakan salh satu aspek penting untuk meningkatkan mutu institusi pendidikan (Priatna, 2018).

Lebih lanjut, mengenai nilai yang dianut, yaitu kumpulan nilai dan norma yang dinyatakat secara eksplisit oleh sebuah institusi (biasanya berbentuk visi dan misi), peneliti tidak menemukan pernyataan tentang sustainabilitas. Peneliti juga tidak menemukan bahwa sustainabilitas menjadi pembicaraan di kalangan pimpinan, dosen, karyawan, atau mahasiswa. Oleh karena itu, peneliti dapat mengatakan bahwa asumsi dasar, yaitu keyakinan dan perilaku yang tertanam secara mendalam di institusi, belum menyentuh elemen sustainabilitas.

Dalam membangun kepemimpinan, interaksi antara pemimpin dan pengikut baik dari dalam dan luar organisasi sangat diperlukan (Maak \& Pless, 2006). Hal tersebut merupakan fenomena relasional sosial dan etika yang dibangun saat individu memperoleh identitas pemimpin atau pengikut (DeRue \& Ashford, 2010). Selama proses berlangsung, ada kemungkinan bahwa seorang pemimpin dapat membangkitkan elemen autentisitas dalam dirinya. Avolio, Luthans, dan Walumbwa (2004, sebagaimana dikutip dalam Avolio \& Gardner, 2005) mendefinisikan pemimpin autentik sebagai orang yang sepenuhnya memahami dengan moral tentang kekuatan dan pengetahuan yang mereka miliki. Pada saat yang sama, mereka juga memiliki perasaan positif yang senada terhadap mitra atau pengikut mereka. Goleman (2004) berpendapat bahwa pengertian ini sangat terkait dengan kecerdasan emosional pemimpin: semacam aspek yang tidak hanya membantu mereka memahami dan 
mengelola diri mereka sendiri, tetapi juga mendukung mereka dalam mengatur dan mengelola manajemen sebuah institusi.

Secara umum, dunia sedang menghadapi tantangan signifikan dalam aspek lingkungan, sosial, dan ekonomi. Oleh karenanya, setiap institusi memerlukan kehadiran pemimpin yang dapat bertanggung jawab dalam mengambil keputusan tepat di tengah berbagai ketidakpastian (Yukl \& Mahsud, 2010), di samping menyadari kekuatan dan keterbatasan mereka (Bottery, Wright, \& James, 2012).

Wacana sustainabilitas sendiri merupakan jembatan pengharapan. Oleh karena itu, Castán Broto dan Westman (2017) percaya bahwa pemimpin mesti menemukan metode yang tepat untuk mengartikulasikan visi kepada para pengikutnya. Selain itu, Koh (2014) berpendapat bahwa tanggung jawab kepemimpinan tidak hanya milik seorang pemimpin tetapi juga timnya. Artinya, begitu gagasan perubahan muncul, seluruh sistem mesti merespon dengan tindakan yang terukur dan sistematis. Penting pula untuk dicatat bahwa dengan menyebarluaskan gagasan sustainabilitas, maka dukungan iklim institusi yang ramah mutlak diperlukan (MuijenHeidi, 2004). Artinya, seluruh proses membutuhkan pemahaman yang nyata tentang apa itu sustainabilitas dan bagaimana hal itu memberikan manfaat bagi orang dalam institusi dan masyarakat pada umumnya. Oleh karena itu, seorang pemimpin perlu menggunakan artikulasi yang tepat, melibatkan dialog bahkan perdebatan, untuk membuat semua orang di organisasi memahami gagasan dan implementasi gagasan tersebut.

Lebih lanjut, pemimpin institusi perlu memperkuat pengetahuan dari setiap pemangku kepentingan, termasuk apabila sebuah institusi memiliki unsur pemegang saham. Fatoki (2016) berpendapat bahwa kedua belah pihak mungkin memiliki pandangan dan tujuan yang berbeda tentang sustainabilitas. Para pemegang saham misalnya hanya memikirkan keuntungan finansial sedangkan di sisi lain, para pemangku kepentingan fokus pada urusan internal dan hubungan dengan pemerintah atau masyarakat. Oleh karena itu, penting untuk menempatkan semua orang di institusi dalam perahu yang sama sebelum memulai inisiatif sustainabilitas.

Kemudian, perlu untuk mengadakan mendalam diskusi dengan dosen dan staf. Cotton, Bailey, Warren, dan Bissell (2009) menemukan bahwa konsep sustainabilitas sulit untuk diintegrasikan ke dalam dalam kurikulum ajar di kampus. Akibatnya, gagasan sustainabilitas tidak menyebar dengan baik di lingkungan universitas, khususnya kepada mahasiswa. Pimpinan kampus bertanggung jawab untuk membantu staf dan tenaga pengajar dalam merumuskan kurikulum yang baik, misalnya dengan mengundang perwakilan dari perguruan tinggi lain yang telah mengimplementasikan gagasan tersebut. Sebagai tambahan, Hopkinson, dkk (2008) percaya ketika pembangunan berkelanjutan ditanamkan dengan benar di dalam sistem dan kurikulum formal dan informal kampus, gagasan itu dapat diterima lebih mudah di kalangan akademisi. Selain itu seperti yang dikemukakan oleh Sofo, 
Fitzgerald, dan Jawas (2012), perlu diterapkan kepemimpinan instruksional yang berfokus pada mahasiswa dan pembelajaran.

Terakhir, kepemimpinan yang berkelanjutan membutuhkan pemahaman untuk menarik mahasiswa mengikuti kampanye. Vázquez, Lanero, dan Licandro (2013) percaya bahwa ide ini dapat ditularkan melalui penjelasan bahwa keberlanjutan akan membawa manfaat bagi prospek karir mahasiswa di masa depan serta kehidupan sehari-hari mereka. Hubungan antara teori dan realitas dapat membuat kepercayaan lebih dalam implementasi sustainabilitas menjadi lebih kuat (Cotton dkk., 2009), serta menjadikan mahasiswa agen sustainabilitas di masa depan (Leal Filho et al., 2018). Para pemimpin juga berharap bahwa hubungan langsung ini dapat meningkatkan dan mengembangkan kemampuan mahasiswa dalam menghadapi tantangan sustainabilitas yang nyata di tengah masyarakat (Huckle 1986, seperti dikutip dalam Gebbels dkk., 2011).

Globalisasi dapat membawa harapan atau malapetaka. Dieck-Assad (2013) berpendapat bahwa pemimpin harus memiliki pemahaman lengkap tentang manfaat, tantangan, dan perangkap globalisasi. Gagasan sustainabilitas membantu pemimpin melihat berbagai aktivitas melalui lensa yang lebih beretika sosial serta lingkungan.

Di sisi lain, universitas dapat menjadi cerminan sebuah kota (May \& Perry, 2017). Setiap perjuangan, agenda, dan wacana yang muncul di perguruan tinggi dapat menjadi cerminan realitas sebuah masyarakat. Jika sebuah universitas, misalnya, bahkan tidak berbicara tentang sustainabilitas, maka praktik. Selain itu, karena wacana keberlanjutan berbicara tentang masalah lingkungan, sosial, dan ekonomi, pengabaian tersebut mungkin hanya akan membuat ketiga aspek tersebut membahayakan di kemudian hari.

Dalam konteks Indonesia, termasuk masyarakat Aceh, ada beberapa tantangan dalam mempraktikkan sustainabilitas. Hal yang menjadi bahasan pertama adalah aspek politik. Wijaya (2007) berpendapat bahwa setiap kegiatan yang berhubungan dengan bisnis atau ekonomi, termasuk institusi pendidikan tinggi, mesti melewati kesepakatan politik terlebih dahulu. Oleh karena itu, tantangan selanjutnya adalah menemukan konsensus politik yang menjadikan sustainabilitas sebagai elemen utama kebijakan, dibandingkan dengan keuntungan finansial semata.

Selanjutnya, Selvarajah, Meyer, Roostika, dan Sukunesan (2017) menemukan bahwa kepemimpinan di Indonesia masih paternalistik dan didominasi oleh ideologi patriarki. Di sisi lain, sebuah temuan mengungkapkan bahwa aspek-aspek feminisme lebih menunjukkan sensitivitas yang lebih baik terhadap tanggung jawab sosial perusahaan (Fatoki, 2016) dan mewakili nilai-nilai yang lebih etis dari sustainabilitas (Wang \& Juslin, 2012). Di kampus sampel sendiri, observasi peneliti menemukan bahwa aspek-aspek patriarki masih kental sehingga secara langsung atau tidak langsung, turut menghambat munculnya gagasan sustainabilitas. 
Terakhir, selain isu sustainabilitas di level perguruan tinggi, Indonesia masih menghadapi tantangan klasik di lintas sektor profesi, seperti misalnya kontraktor (Wirahadikusumah \& Ario, 2015). Studi Wiryomartono (2015) mengungkapkan bahwa kontraktor menyadari regulasi sustainabilitas di Indonesia. Namun hal tersebut belum menjadi ideologi utama yang melandasi kerja profesional mereka. Seperti yang telah peneliti sebutkan di atas, sustainabilitas membutuhkan dukungan dari seluruh anggota masyarakat, lintas sektor. Jika idenya tidak muncul dari kampus, pihak luar juga bisa memancing atau menginspirasi perguruan tinggi untuk melakukannya. Sebaliknya, jika pihak luar seperti kontraktor, pemilik usaha transportasi, pedagang makanan, tidak memiliki ide tersebut, maka pihak universitas dapat memotivasi mereka untuk menjalankannya. Sustainabilitas selalu merupakan proses timbal balik. Terakhir, kampus pun masih terpecah antara satu fakultas dengan fakultas lain dalam mengintegrasikan nilai-nilai keberlanjutan. Sebuah studi di Spanyol misalnya menemukan bahwa jurusan pendidikan justru lebih mudah merealisasikan konsep sustainabilitas dibandingkan jurusan teknik (Sánchez-Carracedo, Carbonell, \& MorenoPino, 2020). Hal ini turut menegaskan pentingnya sinergi lintas keilmuan, antar fakultas, dalam mengimplementasikan isu sustainabilitas di perguruan tinggi.

\section{KESIMPULAN}

Aspek budaya dan lingkungan merupakan unsur penting dalam meningkatkan mutu institusi pendidikan. Perguruan tinggi yang menjadi sampel dalam penelitian ini belum menunjukkan perhatiannya untuk mempromosikan gagasan sustainabilitas, seperti CSR di kampus. Ada satu keberlanjutan peristiwa yang melibatkan universitas dan bank nasional. Namun, perguruan tinggi masih belum bisa menunjukkan bahwa praktik yang sama adalah inisiatif dari kampus dan direncanakan secara berkelanjutan di masa depan. Namun di samping itu, peneliti menemukan beberapa peristiwa yang terkait dengan sustainabilitas, walau masih dalam konteks 'tersembunyi'. Peneliti menggunakan istilah itu untuk menegaskan bahwa tidak ada rilis yang jelas atau langsung dari kampus terkait masalah tersebut. Selain itu, evaluasi dari artefak universitas, nilai-nilai yang dianut, dan asumsi dasar menunjukkan bahwa sustainabilitas bukanlah bagian dari budaya kampus.

Isu sustainabilitas membutuhkan keterlibatan semua pihak, termasuk akademisi, pemerintah, stakeholder, dan masyarakat luas. Selain itu, diperlukan usaha yang serius untuk mengintegrasikan ide sustainabilitas ke dalam kurikulum dan memberikan kesempatan kepada masiswa untuk menghubungkannya dengan realitas mereka.

Mengenai aspek kepemimpinan, para pimpinan perguruan tinggi perlu beradaptasi dan menyesuaikan gaya kepemimpinan mereka berdasarkan kondisi dan situasi untuk mengakomodasi nilai-nilai sustainabilitas. Alasannya, tidak jarang perbedaan di perguruan tinggi sendiri (misalnya lintas program studi), dapat menjadi 
tantangan dalam mewujudkan ide sustainabilitas. Di samping itu, perguruan tinggi juga mesti membuat kampanye yang masif ke masyarakat, misalnya dengan menerbitkan artikel-artikel populer di media massa. Selain itu, sebagaimana dikemukakan dalam pendahuluan, ajaran Islam itu sendiri telah mencakup pengertian tentang keharmonisan antara manusia, lingkungan, semua makhluk di muka bumi. Perguruan tinggi dapat menjadi contoh dan menjadi panutan sustainabilitas, walaupun hal ini sulit dan tidak semua kampus mampu melaksanakannya dalam waktu yang cepat. Sustainabilitas semestinya bukan hanya berhenti sebagai ide atau wacana, ia mesti menjadi realitas di perguruan tinggi dan di masyarakat.

\section{REFERENSI}

Attas, M. N. al, \& Ashraf, S. A. (1979). Aims and objectives of Islamic education. Hodder and Stoughton.

Avolio, B. J., \& Gardner, W. L. (2005). Authentic leadership development: Getting to the root of positive forms of leadership. The Leadership Quarterly, 16(3), 315338.

Basiago, A. D. (1995). Sustainable development in Indonesia: A case study of an indigenous regime of environmental law and policy. The International Journal of Sustainable Development \& World Ecology, 2(3), 199-211.

Beck, C. (1974). Educational philosophy and theory: An introduction (1st ed.). Boston: Little Brown \& Company.

Beringer, A., \& Adomßent, M. (2008). Sustainable university research and development: inspecting sustainability in higher education research. Environmental Education Research, 14(6), 607-623.

Bottery, M., Wright, N., \& James, S. (2012). Personality, moral purpose, and the leadership of an education for sustainable development. Education 3-13, 40(3), 227-241.

Bowen, G. A. (2009). Document analysis as a qualitative research method. Qualitative Research Journal.

Castán Broto, V., \& Westman, L. (2017). Just sustainabilities and local action: Evidence from 400 flagship initiatives. Local Environment, 22(5), 635-650.

Cotton, D., Bailey, I., Warren, M., \& Bissell, S. (2009). Revolutions and second-best solutions: education for sustainable development in higher education. Studies in Higher Education, 34(7), 719-733.

Darder, A., Baltodano, M. P., \& Torres, R. D. (Eds.). (2017). The Critical Pedagogy Reader. New York: Routledge. 
DeRue, D. S., \& Ashford, S. J. (2010). Who will lead and who will follow? A social process of leadership identity construction in organizations. Academy of Management Review, 35(4), 627-647.

Dieck-Assad, M. de L. (2013). Globalization and the business schools: Toward business and world-sustainable leadership. Journal of Teaching in International Business, 24(3-4), 168-187.

Fatoki, O. (2016). Gender and the perception of corporate social responsibility by university students in South Africa. Gender and Behaviour, 14(3), 7574-7588.

Ferdig, M. A. (2007). Sustainability leadership: Co-creating a sustainable future. Journal of Change Management, 7(1), 25-35.

Fitria, S., \& Hartanti, D. (2010). Islam and social responsibility: Comparative study of disclosure based on the global reporting initiative index and islamic social reporting index. National Accounting Symposium, 13.

Gebbels, S., Evans, S. M., \& Delany, J. E. (2011). Promoting environmental citizenship and corporate social responsibility through a school/industry/university partnership. Journal of Biological Education, 45(1), 13-19.

Goleman, D. (2004). What makes a leader? Harvard Business Review, 82(1), 82-91.

Hopkinson, P., Hughes, P., \& Layer, G. (2008). Sustainable graduates: linking formal, informal and campus curricula to embed education for sustainable development in the student learning experience. Environmental Education Research, 14(4), $435-454$.

Watchdoc Image. (Producer). (2015, November 29). [Video file]. Retrieved from https://www.youtube.com/watch?v=ZVONkADi2dc\&t=1s

Koh, C. (2014). The responsible leadership for performance framework. In H. Hasan (Ed.), Being Practical with Theory: A Window into Business Research (pp. 67-70). Wollongong: THEORI.

Leal Filho, W., Raath, S., Lazzarini, B., Vargas, V. R., De Souza, L., Anholon, R., ... Orlovic, V. L. (2018). The role of transformation in learning and education for sustainability. Journal of Cleaner Production, 199, 286-295.

Maak, T., \& Pless, N. M. (2006). Responsible leadership in a stakeholder society-a relational perspective. Journal of Business Ethics, 66(1), 99-115.

May, T., \& Perry, B. (2017). Knowledge for just urban sustainability. Local Environment, 22(sup1), 23-35.

MuijenHeidi, H. S. C. A. (2004). Corporate social responsibility starts at university. Journal of Business Ethics, 53(1-2), 235-246. 
Nejati, M., Shafaei, A., Salamzadeh, Y., \& Daraei, M. (2011). Corporate social responsibility and universities: A study of top 10 world universities' websites. African Journal of Business Management, 5(2), 440-447.

Priatna, T. (2018). TOTAL QUALITY MANAJEMEN UNTUK PENINGKATAN MUTU MADRASAH. Jurnal Isema: Islamic Educational Management, 3(1).

Rosser, A., \& Edwin, D. (2010). The politics of corporate social responsibility in Indonesia. The Pacific Review, 23(1), 1-22.

Sánchez-Carracedo, F., Carbonell, B. S., \& Moreno-Pino, F. M. (2020). Analysis of sustainability presence in Spanish higher education. International Journal of Sustainability in Higher Education.

Savenye, W. C., \& Robinson, R. S. (2005). Using qualitative research methods in higher education. Journal of Computing in Higher Education, 16(2), 65-95.

Schein, E. H. (2010). Organizational culture and leadership (4th ed.). San Fransisco: Jossey-Bass.

Selvarajah, C., Meyer, D., Roostika, R., \& Sukunesan, S. (2017). Exploring managerial leadership in Javanese (Indonesia) organisations: engaging Asta Brata, the eight principles of Javanese statesmanship. Asia Pacific Business Review, 23(3), 373395.

Sofo, F., Fitzgerald, R., \& Jawas, U. (2012). Instructional leadership in Indonesian school reform: overcoming the problems to move forward. School Leadership \& Management, 32(5), 503-522.

Székely, F., \& Knirsch, M. (2005). Responsible leadership and corporate social responsibility:: Metrics for sustainable performance. European Management Journal, 23(6), 628-647.

Vázquez, J. L., Lanero, A., \& Licandro, O. (2013). CORPORATE SOCIAL RESPONSIBILITY AND HIGHER EDUCATION: URUGUAY UNIVERSITY STUDENTS'PERCEPTIONS1. Economics \& Sociology, 6(2), 145.

Wang, L., \& Juslin, H. (2012). Values and corporate social responsibility perceptions of Chinese university students. Journal of Academic Ethics, 10(1), 57-82.

Wijaya, Y. (2007). Can Business Ethics be Interreligious? An Indonesian Perspective. In Stückelberger, C., Mugambi, J. N. K. (2007). Responsible Leadership: Global and Contextual Ethical Perspectives. WCC Publications.

Wirahadikusumah, R. D., \& Ario, D. (2015). A readiness assessment model for Indonesian contractors in implementing sustainability principles. International Journal of Construction Management, 15(2), 126-136. 
Evaluasi: Jurnal manajemen Pendidikan Islam

ISSN (P): 2580-3387, ISSN (E): 2615-2886

Vol. 5 No. 2 September 2021

Wiryomartono, B. (2015). 'Green building'and sustainable development policy in Indonesia since 2004. International Journal of Sustainable Building Technology and Urban Development, 6(2), 82-89.

Yukl, G., \& Mahsud, R. (2010). Why flexible and adaptive leadership is essential. Consulting Psychology Journal: Practice and Research, 62(2), 81. 